\title{
Carbonyl-to-Alkyne Electron Donation Effects in up to 10-nm-Long, Unimolecular Oligo( $p$-phenylene ethynylenes)
}

\author{
Sinu C. Rajappan ${ }^{\# a, 1}$ (D) \\ Olav Vestrheim ${ }^{\# a}$ \\ Mona Sharafi ${ }^{a}$ \\ Jianing $\mathrm{Li}^{\mathbf{a}}$ (i) \\ Severin T. Schneebeli*a (iD) \\ a University of Vermont, Departments of Chemistry and Materials Science, 82 \\ University Place, Burlington, VT 05405, United States \\ severin.schneebeli@uvm.edu \\ "These authors have contributed equally to this work.
}

Received: 24.01.2021

Accepted after revision: 30.04 .2021

DOI: 10.1055/s-0041-1730899; Art ID: om-21-0014sc

License terms: CC)

(c) 2021. The Author(s). This is an open access article published by Thieme under the terms of the Creative Commons Attribution-NonDerivative-NonCommercial License, permitting copying and reproduction so long as the original work is given appropriate credit. Contents may not be used for commercial purposes, or adapted, remixed, transformed or built upon. (https://creativecommons.org/licenses/by-nc-nd/4.0/)

Abstract We synthesized some of the longest unimolecular oligo( $p$ phenylene ethynylenes) (OPEs), which are fully substituted with electron-withdrawing ester groups. An iterative convergent/divergent (a.k.a. iterative exponential growth - IEG) strategy based on Sonogashira couplings was utilized to access these sequence-defined macromolecules with up to 16 repeating units and 32 ester substituents. The carbonyl groups of the ester substituents interact with the triple bonds of the OPEs, leading to (i) unusual, angled triple bonds with increased rotational barrier, (ii) enhanced conformational disorder, and (iii) associated broadening of the UV/Vis absorption spectrum. Our results demonstrate that fully air-stable, unimolecular OPEs with ester groups can readily be accessed with IEG chemistry, providing new macromolecular backbones with unique geometrical, conformational, and photophysical properties.

Key words sequence-defined macromolecules, shape-defined macromolecules, Sonogashira coupling, iterative exponential growth, density functional theory, $\pi$-conjugation

\section{Introduction}

Poly( $p$-phenylene ethynylenes) (PPEs) $)^{2}$ are special in that they belong (together with other poly( $p$-phenylene $) s)^{3}$ to a class of conjugated, non-ladder polymers, whose backbone structures are fully shape-defined. This shape persistence arises from the fact that, with fully linear triple bonds, rotation around any of the single/triple bonds present in the backbone of a PPE does not change a PPE's overall end-to-end distance. With other macromolecules, a similar degree of shape persistence can only be obtained by

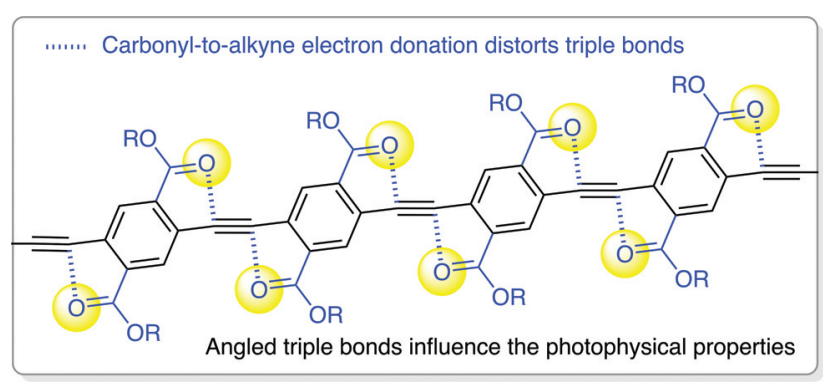

introducing rings into the backbones, for example, with

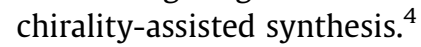

Due to their linearity, high degree of $\pi$-conjugation, and associated electronic communication between the different phenylene units, $\pi$-conjugated macromolecules ${ }^{5}$ (including PPEs) have found applications in the fields of sensing, ${ }^{3 b, 3 e, 3 j, 6}$ organic electronics, ${ }^{3 \mathrm{~h}, 7}$ and biological imaging. ${ }^{2 \mathrm{~d}, 3 \mathrm{j}, 8}$ However, open questions still remain as to how the geometrical and photophysical properties of PPEs are affected by electron-withdrawing substituents ${ }^{3 g, 9}$ like ester groups. Initial studies in this regard have focused on esterfunctionalized PPE systems with a distribution of different lengths. ${ }^{10}$ However, a size distribution in chain lengths can make it difficult to correlate the detailed photophysical properties with chain length, since the spectra are naturally broadened due to the inherent length distributions present in each sample. While more challenging to access, ${ }^{11}$ the study of unimolecular macromolecules offers valuable additional information, in particular as to how absorption linewidths are affected by conformational disorder. ${ }^{12}$ Yet, the prior literature investigating ${ }^{13}$ unimolecular models of PPEs has been focused primarily on unsubstituted and/or alkoxy-substituted oligo( $p$-phenylene ethynylenes) (OPEs), which behave quite differently from ester-functionalized OPE systems, as detailed in the Results and Discussions section. Here we now synthesized some of the largest, unimolecular, ester-functionalized OPEs with iterative exponential growth ${ }^{14}$ (IEG).

\section{Results and Discussion}

We started this work with density functional theory (DFT) calculations ${ }^{15}$ to predict the exact geometries of the triple bonds in OPEs with various substituents. To account for dispersion interactions, we utilized the B3LYP-MM functional ${ }^{16}$ with the cc-pVDZ++ basis set (for single-point calculations) and the LACVP* basis set (for geometry optimizations). The B3LYP-MM parameters were carefully 
optimized with a large dataset of non-covalent interaction energies to accurately reproduce dispersion interactions, even in the presence of basis set superposition error. ${ }^{16 e}$

As a simple model for ester-functionalized OPEs, we utilized tetramethyl 2,2'-(ethyne-1,2-diyl)diterephthalate (1) for our DFT analysis. To our surprise, we noted that in the optimized structure of $\mathbf{1}$ (lowest energy structure in vacuum, see Figure $3 \mathrm{~B}$ for an alternative low-energy conformation), the triple bonds are bent (Figure 1A), with $\mathrm{C}-\mathrm{C} \equiv \mathrm{C}$ angles of $171.7^{\circ}$. This finding is in stark contrast to the larger $\mathrm{C}-\mathrm{C} \equiv \mathrm{C}$ angles of $180.0^{\circ}$ and $177.9^{\circ}$, which we observed at the same level of theory for the corresponding unsubstituted (1,2-diphenylethyne) as well as for methoxyl-substituted (1,2-bis(2,5-dimethoxyphenyl)ethyne) systems (see the Supporting Information for the optimized structures). We then calculated the

\section{A. DFT-optimized model of repeat unit}

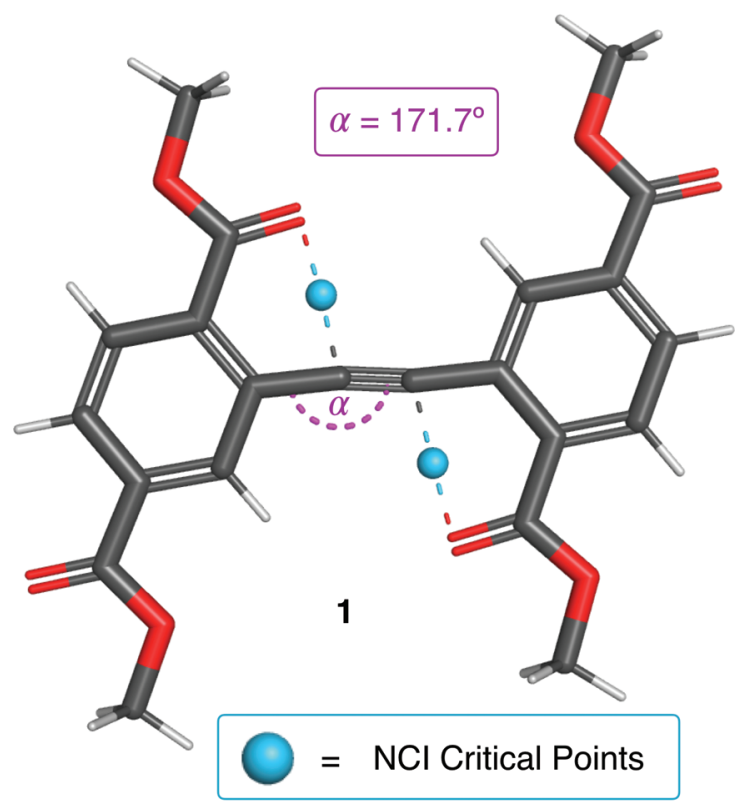

\section{Single crystal X-ray structure (ref. 31)}

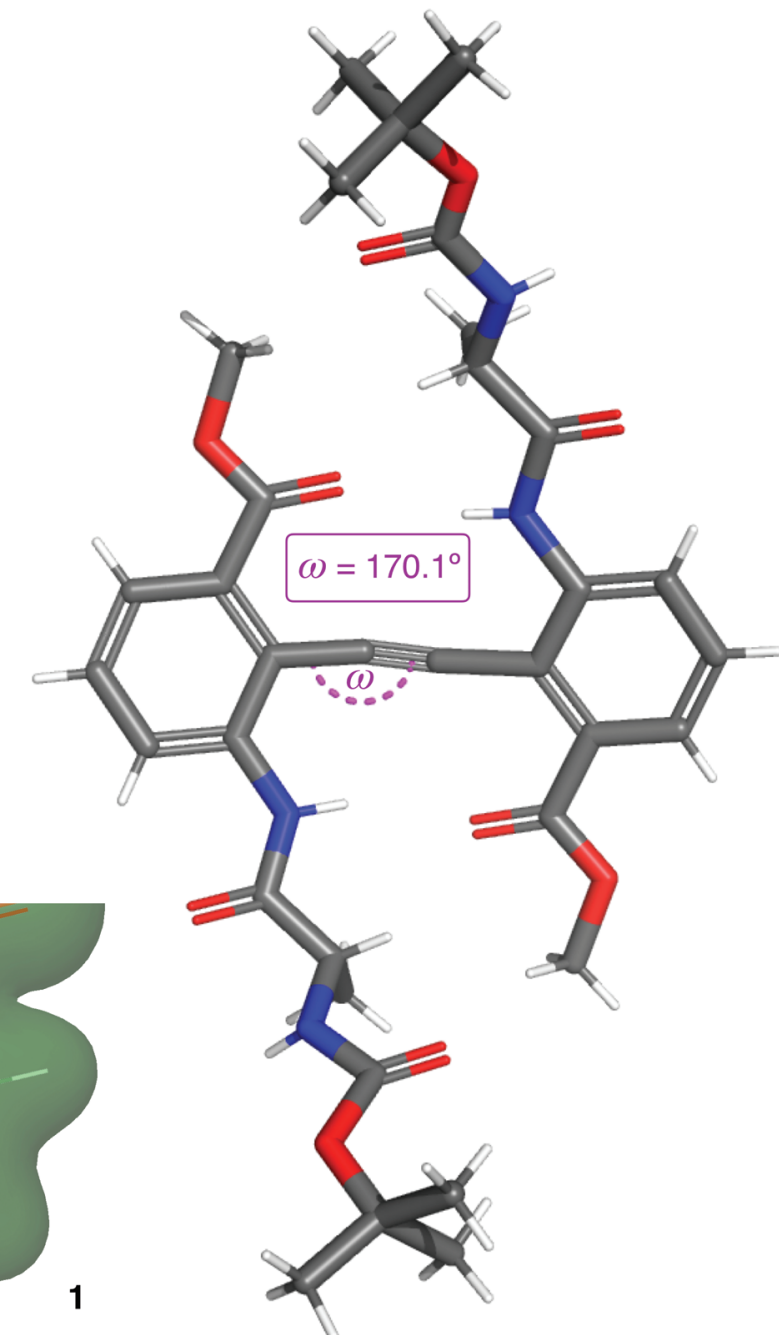

Figure 1 A. DFT-optimized tetramethyl 2,2'-(ethyne-1,2-diyl)diterephthalate (1) as a model for an OPE repeat unit. The DFT-optimized structure (lowest energy conformation in vacuum, see Figure 3B for an alternate low-energy conformation) illustrates how the triple bonds in the OPEs bend due to carbonyl-to-alkyne electron donation effects. NCl critical points, calculated with the Jaguar software package from the electron density (see Panel B), are illustrated with blue spheres. As has been established by Johnson et al. (see Ref. 17), these $\mathrm{NCl}$ critical points represent attractive supramolecular interactions ( $\mathrm{NCl}$ interaction strength $=9.0 \mathrm{kcal} \mathrm{mol}^{-1}$ in vacuum and $9.1 \mathrm{kcal} \mathrm{mol}^{-1}$ in $\mathrm{CHCl}_{3}$ with a PBF solvent model). B. DFT-calculated electron density (isosurface at 0.014 a.u.) of tetramethyl 2,2'-(ethyne-1,2-diyl)diterephthalate (1). Arrows indicate the enhanced sections of the electron density, which correspond to the attractive supramolecular interactions between the carbonyl groups and the alkyne units of 1 identified by the NCl analysis shown in Panel A. C. Single-crystal X-ray structure of a model compound (dimethyl 2,2'-(ethyne-1,2-diyl)bis(3-(2-((t-butoxycarbonyl)amino)propanamido)benzoate), reported in Ref. 19, CCDC 915930), which clearly shows the bent triple bonds arising due to carbonyl-to-alkyne interactions. 
critical points of the electron density and used them to visualize (Figure 1A) the non-covalent interactions that are primarily responsible for the bending of the triple bonds with the NCI code ${ }^{17}$ implemented in the Jaguar ${ }^{18}$ software package. The $\mathrm{NCI}$ critical points, which were calculated from the electron density (Figure 1B), clearly demonstrate the presence of attractive, supramolecular interactions between the carbonyl groups of the ester groups, and the triple bonds. This result is consistent with triple-bond bending, driven by carbonyl-to-alkyne electron donation. Further experimental evidence for these interactions stems from a published ${ }^{19}$ crystal structure (Figure $\left.1 \mathrm{C}\right)$ of a model compound (dimethyl 2,2'-(ethyne-1,2-diyl)bis(3-(2-((tbutoxycarbonyl)amino)-propanamido)benzoate), which also shows the bent triple bonds arising from the carbonyl-to-alkyne interactions).

Next, we discovered that the carbonyl-to-alkyne interactions also significantly alter the barriers for rotation around the triple bonds in the OPEs. Notably, we found (Figure 2) the barrier for rotation around the triple bond in the ester-functionalized model system tetramethyl-2,2'(ethyne-1,2-diyl)diterephthalate (1) to be nearly twice as high as in the unsubstituted model system, 1,2-diphenylethyne (2). This finding is explained by the carbonyl-toalkyne interactions, which desymmetrize (Figure 2C) the two orthogonal $\pi$-bonds of the alkynes in the backbone of the OPEs.
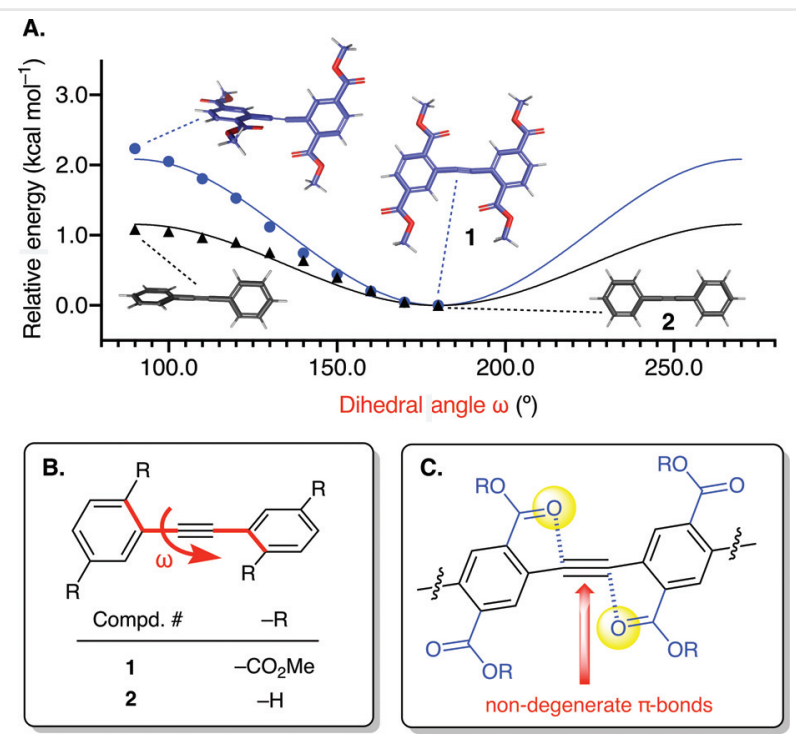

Figure 2 A. Carbonyl-to-alkyne electron donation effects on the torsional profiles (triple bond rotation) of 2,2'-(ethyne-1,2-diyl)diterephthalate (1) and 1,2-diphenylethyne. Torsional profiles were calculated at the B3LYP-MM/cc-pVDZ + +//B3LYP-MM/LACVP* level of theory in vacuum. B. Definition of the dihedral angles $\omega$ used as the abscissa for the torsional plots. C. Carbonyl-to-alkyne electron donation effects lead to angled triple bonds with non-degenerate $\pi$-bonds.
Based on these computational results, which demonstrate the unique geometrical and conformational properties of ester-functionalized OPEs, we next set out to synthesize such macromolecules in a unimolecular fashion. As shown in Scheme 1, the synthesis of up to $\sim 10 \mathrm{~nm}$ long, unimolecular OPEs was accomplished with Sonogashira coupling-based IEG synthesis. ${ }^{20}$

The starting material, bis(2-ethylhexyl)-2-amino-5((triisopropylsilyl)ethynyl)terephthalate (3), was synthesized as detailed in the Supporting Information. Briefly, 2-amino-5-iodo-1,4-benzenedicarboxylic acid (synthesized as described previously in the literature $)^{21}$ was deprotonated with potassium carbonate, and the resulting bis (carboxylate) derivative alkylated with 3-(bromomethyl) heptane. Sonogashira coupling with (triisopropylsilyl)acetylene then afforded bis(2-ethylhexyl)-2-amino-5-((triisopropylsilyl)ethynyl)terephthalate (3) as the starting point for IEG growth.

As detailed in Scheme 1, IEG growth of the OPEs then consisted of three simple steps, which were applied iterative$\mathrm{ly}^{22}$ (i) About half of the triisopropylsilyl (TIPS)-protected sample at each growth stage is deprotected with tetrabutylammonium fluoride (TBAF) to afford the terminal alkyne derivative (which can directly engage as the alkyne donor in a Sonogashira cross-coupling).(ii) The other half of the sample is then activated to become the alkyne acceptor for the Sonogashira coupling step by converting the terminal aniline group into an aryl iodide, via a one-pot diazotization/iodination ${ }^{23}$ reaction sequence. (iii) Finally, the aryl iodide component is linked to the component containing the free acetylene group in a Sonogashira coupling step to double the chain length. Notably, the presence of the electron-withdrawing ester groups along the OPE backbone renders all the intermediates (including the unprotected acetylenes) fully air-stable. Related intermediates for alkoxysubstituted OPE derivatives can show air-sensitivity for increased polymer lengths, a challenge ${ }^{24}$ which seems to be completely avoided by our ester-functionalized backbones.

With this IEG approach we were able to isolate the OPEs 4-7. ${ }^{25-29} 7$ represents, to the best of our knowledge, the longest fully ester-functionalized OPE synthesized to date. With 7 in hand, we set out to investigate the effects of the ester substituents on the photo-physics of the unimolecular OPEs. The UV/Vis absorption spectrum of $\mathbf{7}$ displayed (Figure 3A) a similar absorption maximum (at $405 \mathrm{~nm}$ ) as the previously reported ${ }^{30}$ heptadecameric OPE 8, which contains both unsubstituted phenylenes and alkoxy-substituted phenylene units. Interestingly, however, the UV/Vis absorption spectrum of $\mathbf{7}$ was clearly broadened (Figure $3 \mathrm{~A}$ ), compared to the UV/Vis absorption spectrum of $\mathbf{8}$. Significant line-broadening was also observed (see Supplementary Figures S15 and S16) for the shorter oligomers 5 and 6.

DFT calculations (performed like before at the B3LYP-MM/cc-pVDZ++//B3LYP-MM/LACVP* level ${ }^{16}$ of 


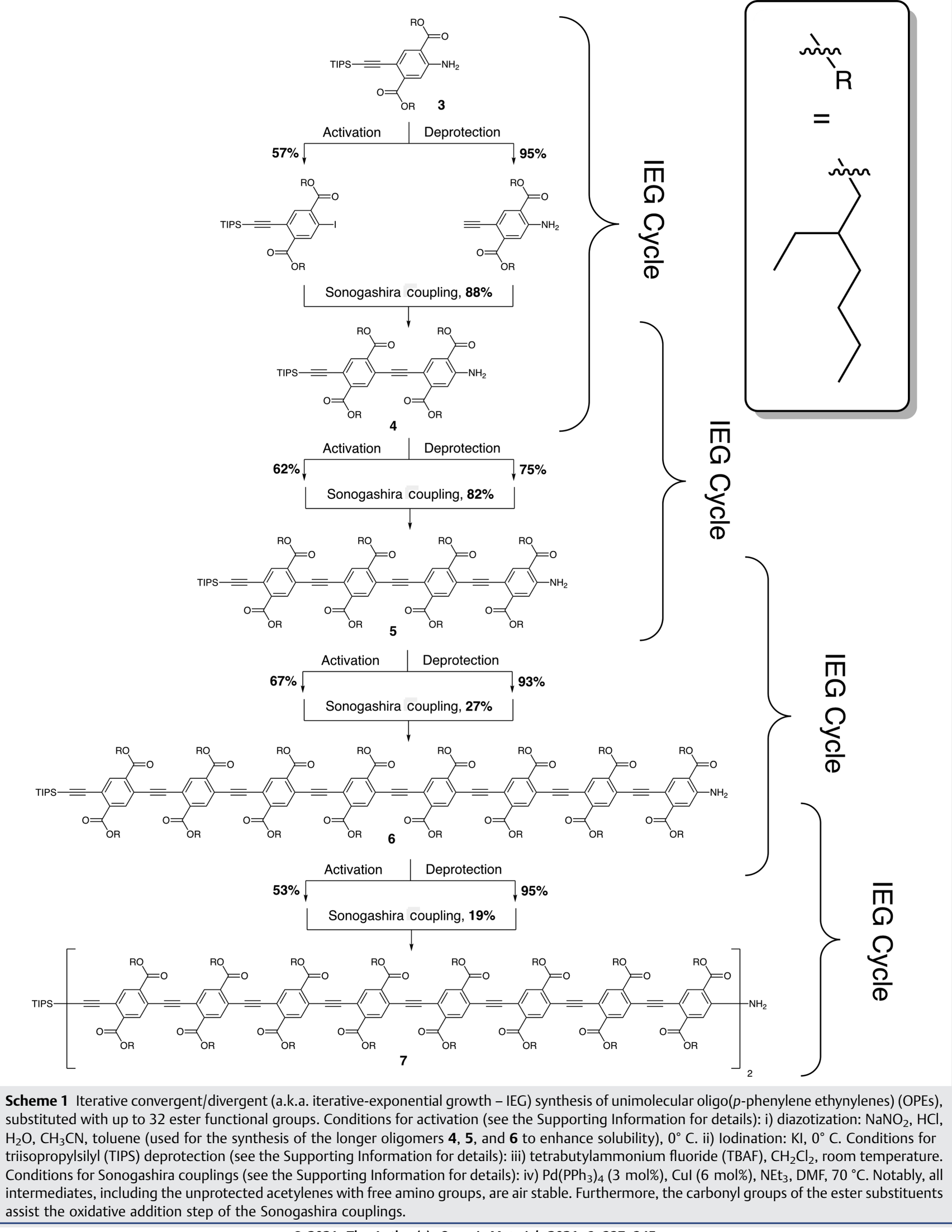

() 2021. The Author(s). Organic Materials 2021, 3, 337-345 

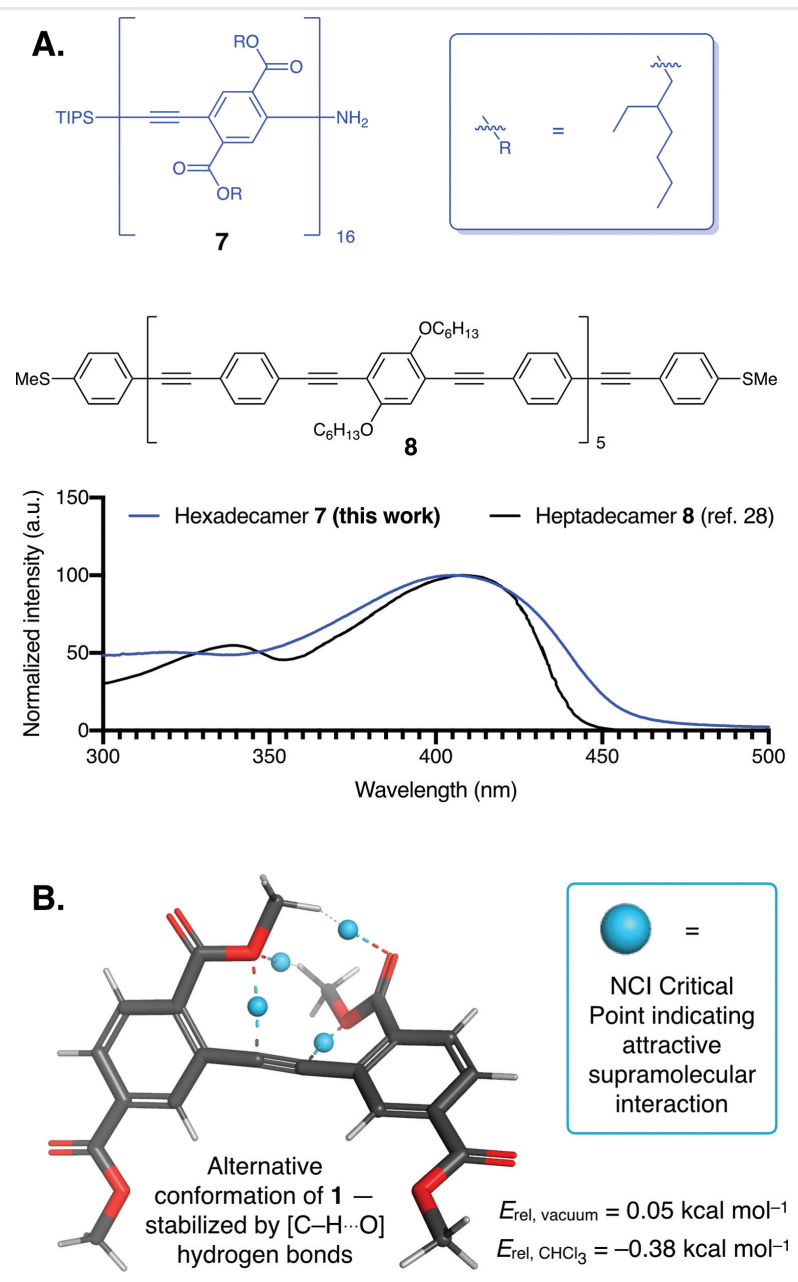

Figure 3 Enhanced conformational disorder resulting from carbonylto-alkyne-derived alkyne-bending contributes to broadening of the UV/Vis absorption spectrum of the hexadecamer 7. A. Comparison of the UV/Vis absorption spectrum $\left(\mathrm{CHCl}_{3}\right)$ of $\mathbf{7}$ to the UV/Vis absorption spectrum $\left(\mathrm{CHCl}_{3}\right)$ of the mixed unsubstituted/alkoxy-substituted OPE 8. The UV/Vis absorption data for $\mathbf{8}$ were extracted with the WebPlotDigitizer from Ref. 30. Broadening of the UV/Vis absorption spectrum for the OPE 7 with the ester groups is observed, compared to the OPE 8, which lacks the ability to engage in carbonyl-to-alkyne electron donation. B. Alternative low-energy conformation of the OPE model compound 1 . Relative energy (relative to the conformation shown in Figure $1 \mathrm{~A}$ ) in vacuum, $E_{\text {rel, vacuum }}=0.05 \mathrm{kcal} \mathrm{mol}^{-1}$. Relative energy with the $\mathrm{CHCl}_{3}$ Poisson-Boltzmann finite element (PBF) solvent model implemented in Jaguar, $E_{\text {rel, }} \mathrm{CHCl}=-0.38 \mathrm{kcal} \mathrm{mol}^{-1}$. We hypothesize that this secondary low-energy conformation (which is accessible to each of the 15 internal triple bonds of the ester-functionalized OPE 7) contributes to the observed (Figure $3 \mathrm{~A}$ ) line broadening of the UV/Vis absorption spectrum of 7 . The relative energies were calculated at the B3LYP-MM/cc-pVDZ + +//B3LYP-MM/LACVP* level of theory. Similar line broadening is observed for the shorter oligomers $\mathbf{5}$ and $\mathbf{6}$ (see Supplementary Figures S15 and S16).

theory to account for dispersion interactions as well as basis set superposition error) were able to explain the observed broadening of the UV/Vis absorption spectrum caused by the ester substituents on the OPE 7. Specifically, the DFT calculations showed that, due to the bent triple bonds, an alternate low-energy conformation exists for each triple bond. This secondary low-energy conformation is only $0.05 \mathrm{kcal} \mathrm{mol}^{-1}$ higher in energy than the most stable conformation (shown in Figure 1) in vacuum, while it becomes slightly favored in energy when applying a Poisson-Boltzmann finite element (PBF) solvent model in $\mathrm{CHCl}_{3}$. In general, solvation favors the alternate low-energy conformation shown in Figure $3 \mathrm{~B}$, as it possesses a larger dipole moment (3.4 debye) than the conformation shown in Figure $1 \mathrm{~A}$ ( 0.0 debye). The alternate conformation of the triple bond, in which both ortho-ester groups are located on the same side of the triple bond, is stabilized by $\left[\mathrm{C}-\mathrm{H}^{\cdots} \mathrm{O}\right]-$ hydrogen bonds, ${ }^{31}$ which are shown as critical points of the electron density (blue spheres) in Figure 3B. Given the small energetic differences between these two very distinct conformations, we conclude that both of these low-energy conformations very likely coexist in solution for each of the 15 triple bonds in 7, which induces significant conformational disorder, and associated conformational line broadening of the UV/Vis absorption spectrum of $7 .^{32}$

\section{Conclusions}

We investigated the effects of electron-withdrawing ester functions on the geometry and photophysical properties of OPEs, for the first time with unimolecular, ester-functionalized OPEs up to $\sim 10 \mathrm{~nm}$ in length (with up to 16 repeating units). We demonstrated that - in contrast to unsubstituted and alkoxy-substituted OPEs - the triple bonds in the esterfunctionalized OPEs have a tendency to bend, departing from their idealized, fully linear conformations. The observed bending of the triple bonds in the ester-functionalized OPEs is driven by carbonyl-to-alkyne electron donation effects, which also increase the rotational barriers around the triple bonds, and lead to enhanced conformational disorder and broadening of the UV/Vis absorption spectra. Our results advance the fundamental understanding of how the geometrical and associated photophysical properties of unimolecular, $\pi$-conjugated oligomers and polymers can be tuned with electron-withdrawing ester substituents. We are currently utilizing our new unimolecular, ester-functionalized macromolecules as templates for polymer replication, as well as for sensing applications.

\section{Funding Information}

This work was supported by the Army Research Office (Grant 71015-CH-YIP awarded to S.T.S.). J.L. was partially supported by an NSF CAREER award (Grant CHE-1945394). The UVM Mass Spectrometry facilities were supported by 
National Institutes of Health (Grants S10-OD018126 and P30-GM118228). Part of the computational facilities was also supported by an NSF CAREER award (Grant CHE1848444 awarded to STS).

\section{Acknowledgment}

We thank Dr. M. Ivancic for help with NMR spectroscopy, as well as Dr. F. Sun and B. O'Rourke for acquiring MALDI and high-resolution-ESI mass spectra, respectively.

\section{Supporting Information}

Supporting Information for this article is available online at https://doi.org/10.1055/s-0041-1730899.

\section{References and Notes}

(1) New address: Sinu C. Rajappan, School of Polymer Science and Engineering, University of Southern Mississippi, 118 College Drive, Hattiesburg, MS 39406, USA.

(2) (a) Palmans, A.; Montali, A.; Weder, C.; Smith, P. Proc. MRS 1999, 560, 265. (b) Sen, C. P.; Valiyaveettil, S. J. Polym. Sci., Part A: Polym. Chem. 2016, 54, 3652. (c) Liang, J.; Wu, P.; Tan, C.; Jiang, Y. RSC Adv. 2018, 8, 9218. (d) Braeken, Y.; Cheruku, S.; Seneca, S.; Smisdom, N.; Berden, L.; Kruyfhooft, L.; Penxten, H.; Lutsen, L.; Fron, E.; Vanderzande, D.; Ameloot, M.; Maes, W.; Ethirajan, A. ACS Biomater. Sci. Eng. 2019, 5, 1967. (e) Hleli, E.; Mbarek, M.; Gouid, Z.; Ulbricsht, C.; Romdhane, S.; Ben Said, R.; Guesmi, M.; Egbe, D. A. M.; Bouchriha, H. J. Phys. Chem. Solids 2020, 136, 109157. (f) Jagadesan, P.; Yu, Z.; Barboza-Ramos, I.; Lara, H. H.; Vazquez-Munoz, R.; Lopez-Ribot, J. L.; Schanze, K. S. Chem. Mater. 2020, 32, 6186. (g) Nie, J.; Wang, Z.; Huang, X.; Lu, G.; Feng, C. Macromolecules 2020, 53, 6299. (h) Wang, Q.; Zhong, Y.; Miller, D. P.; Lu, X.; Tang, Q.; Lu, Z.-L.; Zurek, E.; Liu, R.; Gong, B. J. Am. Chem. Soc. 2020, 142, 2915. (i) Zhang, Y.; Zhan, H.; Chen, J.; Sun, L.; Fan, L.-J. J. Polym. Sci. 2020, 58, 2088.

(3) (a) Remmers, M.; Schulze, M.; Wegner, G. Macromol. Rapid Commun. 1996, 17, 239. (b) Levitsky, I. A.; Kim, J.; Swager, T. M. J. Am. Chem. Soc. 1999, 121, 1466. (c) Brizius, G.; Pschirer, N. G.; Steffen, W.; Stitzer, K.; zur Loye, H.-C.; Bunz, U. H. F. J. Am. Chem. Soc. 2000, 122, 12435. (d) Kim, J.; McQuade, D. T.; McHugh, S. K.; Swager, T. M. Angew. Chem. Int. Ed. 2000, 39, 3868. (e) McQuade, D. T.; Hegedus, A. H.; Swager, T. M. J. Am. Chem. Soc. 2000, 122, 12389. (f) McQuade, D. T.; Kim, J.; Swager, T. M. J. Am. Chem. Soc. 2000, 122, 5885. (g) Kim, J.; Swager, T. M. Nature 2001, 411, 1030. (h) Schmitz, C.; Posch, P.; Thelakkat, M.; Schmidt, H.-W.; Montali, A.; Feldman, K.; Smith, P.; Weder, C. Adv. Funct. Mater. 2001, 11, 41. (i) Nesterov, E. E.; Zhu, Z.; Swager, T. M. J. Am. Chem. Soc. 2005, 127, 10083. (j) Moon, J. H.; McDaniel, W.; MacLean, P.; Hancock, L. F. Angew. Chem. Int. Ed. 2007, 46, 8223. (k) Satrijo, A.; Swager, T. M. J. Am. Chem. Soc. 2007, 129, 16020. (1) Egbe, D. A. M.; Tuerk, S.; Rathgeber, S.; Kuehnlenz, F.; Jadhav, R.; Wild, A.; Birckner, E.; Adam, G.; Pivrikas, A.; Cimrova, V.; Knor, G.; Sariciftci, N. S.; Hoppe, H. Macromolecules 2010, 43, 1261. (m) Jagadesan, P.; Valandro, S. R.; Schanze, K. S. Mater. Chem. Front. 2020, 4, 3649. (n) Liu, K.; Shen, Y.; Li, X.; Zhang, Y.; Quan, Y.;
Cheng, Y. Chem. Commun. 2020, 56, 12829. (o) Luo, S. L.; Lin, C.-J.; Ku, K. H.; Yoshinaga, K.; Swager, T. M. ACS Nano 2020, 14, 7297.

(4) (a) Liu, X.; Weinert, Z. J.; Sharafi, M.; Liao, C.; Li, J.; Schneebeli, S. T. Angew. Chem. Int. Ed. 2015, 54, 12772. (b) Beaudoin, D.; Rominger, F.; Mastalerz, M. Angew. Chem. Int. Ed. 2016, 55, 15599. (c) Beaudoin, D.; Rominger, F.; Mastalerz, M. Angew. Chem. Int. Ed. 2016, 55, 15599. (d) Sharafi, M.; Weinert, Z. J.; Cohen, I. M.; Liao, C.; Ivancic, M.; Li, J.; Schneebeli, S. T. Synlett 2016, 27, 2145. (e) Rommelmann, P.; Greschner, W.; Ihrig, S.; Neumann, B.; Stammler, H.-G.; Groeger, H.; Kuck, D. Eur. J. Org. Chem. 2018, 2018, 3891. (f) Campbell, J. P.; Rajappan, S. C.; Jaynes, T. J.; Sharafi, M.; Ma, Y.-T.; Li, J.; Schneebeli, S. T. Angew. Chem. Int. Ed. 2019, 58, 1035. (g) Campbell, J. P.; Sharafi, M.; Murphy, K. E.; Bocanegra, J. L.; Schneebeli, S. T. Supramol. Chem. 2019, 31, 565.

(5) (a) Nielsen, M. B.; Diederich, F. Chem. Rev. 2005, 105, 1837. (b) Baker, M. A.; Tsai, C.-H.; Noonan, K. J. T. Chem. Eur. J. 2018, 24, 13078.

(6) (a) Breen, C. A.; Deng, T.; Breiner, T.; Thomas, E. L.; Swager, T. M.J. Am. Chem. Soc. 2003, 125, 9942. (b) Smith, R. C.; Tennyson, A. G.; Lim, M. H.; Lippard, S. J. Org. Lett. 2005, 7, 3573. (c) Boden, B. N.; Jardine, K. J.; Leung, A. C. W.; MacLachlan, M. J. Org. Lett. 2006, 8, 1855. (d) VanVeller, B.; Miki, K.; Swager, T. M. Org. Lett. 2010, 12, 1292.

(7) (a) Remmers, M.; Neher, D.; Gruener, J.; Friend, R. H.; Gelinck, G. H.; Warman, J. M.; Quattrocchi, C.; dos Santos, D. A.; Bredas, J.-L. Macromolecules 1996, 29, 7432. (b) Montali, A.; Smith, P.; Weder, C. Synth. Met. 1998, 97, 123. (c) Rozanski, L. J.; Bunz, U. H. F.; Vanden Bout, D. A. Polym. Prepr. (Am. Chem. Soc., Div. Polym. Chem.) 2007, 48, 288. (d) Rozanski, L. J.; Vanden Bout, D. A.; Bunz, U. H. F. In: Excimer Emission in Di-alkyl Poly(p-phenylene ethynylene) LEDs. American Chemical Society: Washington, 2007. (e) Burnworth, M.; Mendez, J. D.; Schroeter, M.; Rowan, S. J.; Weder, C. Macromolecules 2008, 41, 2157.

(8) (a) Zheng, J.; Swager, T. M. Chem. Commun. 2004, 2798. (b) Zhang, L.; Yin, Q.; Huang, H.; Wang, B. J. Mater. Chem. B 2013, 1, 756. (c) Zhang, L.; Huang, H.; Xu, N.; Yin, Q. J. Mater. Chem. B 2014, 2, 4935. (d) D'Olieslaeger, L.; Braeken, Y.; Cheruku, S.; Smits, J.; Ameloot, M.; Vanderzande, D.; Maes, W.; Ethirajan, A.J. Colloid Interface Sci. 2017, 504, 527.

(9) (a) Grem, G.; Leditzky, G.; Ullrich, B.; Leising, G. Adv. Mater. 1992 4, 36. (b) Yamamoto, T.; Morita, A.; Miyazaki, Y.; Maruyama, T.; Wakayama, H.; Zhou, Z. H.; Nakamura, Y.; Kanbara, T.; Sasaki, S.; Kubota, K. Macromolecules 1992, 25, 1214. (c) Son, S.; Dodabalapur, A.; Lovinger, A. J.; Galvin, M. E. Science 1995, 269, 376. (d) Fou, A. C.; Onitsuka, O.; Ferreira, M.; Rubner, M. F.; Hsieh, B. R. J. Appl. Phys. 1996, 79, 7501. (e) Van Duren, J. K. J.; Yang, X.; Loos, J.; Bulle-Lieuwma, C. W. T.; Sieval, A. B.; Hummelen, J. C.; Janssen, R. A. J. Adv. Funct. Mater. 2004, 14, 425. (f) Weber, J.; Thomas, A. J. Am. Chem. Soc. 2008, 130, 6334. (g) Garcia, J. M.; Garcia, F. C.; Serna, F.; de la Pena, J. L. Prog. Polym. Sci. 2010, 35, 623. (h) Lei, T.; Dou, J.-H.; Cao, X.-Y.; Wang, J.-Y.; Pei, J.J. Am. Chem. Soc. 2013, 135, 12168. (i) Lei, T.; Xia, X.; Wang, J.-Y.; Liu, C.-J.; Pei, J.J. Am. Chem. Soc. 2014, 136, 2135. (j) Sun, H.; Martinez, D.; Li, Z.; Schanze, K. S. ACS Appl. Mater. Interfaces 2020, 12, 53310.

(10) Pawle, R. H.; Agarwal, A.; Malveira, S.; Smith, Z. C.; Thomas, S. W. III Macromolecules 2014, 47, 2250.

(11) (a) Gao, H. Macromol. Rapid Commun. 2012, 33, 722. (b) Landry, E.; Ye, Z. Macromol. Rapid Commun. 2013, 34, 1493. (c) Mullner, M.; Muller, A. H. E. Polymer 2016, 98, 389. (d) Wang, Y.; Wang, L.; Chen, G.; Gong, S. Macromol. Biosci. 2017, 17, 1600292. (e) 
Golder, M. R.; Jiang, Y.; Teichen, P. E.; Nguyen, H. V. T.; Wang, W.; Milos, N.; Freedman, S. A.; Willard, A. P.; Johnson, J. A. J. Am. Chem. Soc. 2018, 140, 1596.

(12) (a) Soos, Z. G.; Mukhopadhyay, D.; Hennessy, M. H. Chem. Phys. 1996, 210, 249. (b) Harrison, M. G.; Moller, S.; Weiser, G.; Urbasch, G.; Mahrt, R. F.; Bassler, H.; Scherf, U. Phys. Rev. B: Condens. Matter 1999, 60, 8650. (c) Muller, J. G.; Lemmer, U.; Raschke, G.; Anni, M.; Scherf, U.; Lupton, J. M.; Feldmann, J. Phys. Rev. Lett. 2003, 91, 267403/1. (d) Yang, X.; Dykstra, T. E.; Scholes, G. D. Phys. Rev. B: Condens. Matter 2005, 71, 045203/1. (e) Furmanchuk, A. o.; Leszczynski, J.; Tretiak, S.; Kilina, S. V. J. Phys. Chem. C 2012, 116, 6831.

(13) (a) Ickenroth, D.; Weissmann, S.; Rumpf, N.; Meier, H. Eur. J. Org. Chem. 2002, 2808. (b) Chen, J.; Vachon, J.; Feringa, B. L. J. Org. Chem. 2018, 83, 6025. (c) Hergert, M.; Bender, M.; Seehafer, K.; Bunz, U. H. F. Chem. Eur. J. 2018, 24, 3132. (d) Schneider, R. V.; Waibel, K. A.; Arndt, A. P.; Lang, M.; Seim, R.; Busko, D.; Braese, S.; Lemmer, U.; Meier, M. A. R. Sci. Rep. 2018, 8, 1. (e) Eder, T.; Vogelsang, J.; Bange, S.; Remmerssen, K.; Schmitz, D.; Jester, S.-S.; Keller, T. J.; Hoeger, S.; Lupton, J. M. Angew. Chem. Int. Ed. 2019, $58,18898$.

(14) (a) Barnes, J. C.; Ehrlich, D. J. C.; Gao, A. X.; Leibfarth, F. A.; Jiang, Y.; Zhou, E.; Jamison, T. F.; Johnson, J. A. Nat. Chem. 2015, 7, 810. (b) Leibfarth, F. A.; Johnson, J. A.; Jamison, T. F. Proc. Natl. Acad. Sci. U.S.A 2015, 112, 10617.

(15) All DFT calculations were carried out with the Jaguar software package, with fully analytical integrals (Jaguar keyword: nops $=1$ ) as well as with maximum sized DFT grids (Jaguar keywords: gdftgrad $=-14$, gdftmed $=-14$, and gdftfine $=$ $-14)$. Geometries were optimized with the B3LYP-MM dispersion-corrected functional (see: Ref. 16) with the LACVP* basis set (for which the parameters of the functional have been carefully optimized to also account for basis set superposition error; see: Ref. 16e), followed by single point energy calculations at the B3LYP-MM/cc-pVDZ + + level of theory. The vibrational frequencies for all minimized structures were then calculated at the B3LYP-MM/LACVP* level, and the corresponding zero-point energies were included in the calculation of the relative energies. Solvation energies were calculated via single-point calculations at the B3LYP-MM/LACVP* level, with the $\mathrm{PBF} \mathrm{CHCl}_{3}$ solvent model implemented in the Jaguar software package. Torsional energy profiles were constructed by performing constrained structural optimizations with the dihedral angles $\omega$ (defined in Figure 2B) set to the specified values. Since the harmonic frequency approximation is only applicable to minimized structures (without constrained coordinates) zeropoint energy corrections were not applied to the torsional energy profiles. Non-covalent interaction ( $\mathrm{NCI}$ ) plots as well as $\mathrm{NCI}$ interaction energies were obtained from the reduced density gradient at the B3LYP-MM/LACVP* level, following the methods of Johnson et al. (see: Ref. 17, Jaguar keyword: iplotnoncov $=1$ ). Dipole moments were calculated at the B3LYP-MM/LACVP* level in vacuum.

(16) (a) Vosko, S. H.; Wilk, L.; Nusair, M. Can. J. Phys. 1980, 58, 1200. (b) Lee, C.; Yang, W.; Parr, R. G. Phys. Rev. B Condens. Matter 1988, 37, 785. (c) Becke, A. D. J. Chem. Phys. 1993, 98, 5648. (d) Stephens, P. J.; Devlin, F. J.; Chabalowski, C. F.; Frisch, M. J. J. Phys. Chem. 1994, 98, 11623. (e) Schneebeli, S. T.; Bochevarov, A. D.; Friesner, R. A.J. Chem. Theory Comput. 2011, $7,658$.

(17) Johnson, E. R.; Keinan, S.; Mori-Sánchez, P.; Contreras-García, J.; Cohen, A. J.; Yang, W. J. Am. Chem. Soc. 2010, 132, 6498.
(18) (a) Jaguar, version 10.4. Schrodinger, Inc.: New York, NY, 2019. (b) Bochevarov, A. D.; Harder, E.; Hughes, T. F.; Greenwood, J. R.; Braden, D. A.; Philipp, D. M.; Rinaldo, D.; Halls, M. D.; Zhang, J.; Friesner, R. A. Int. J. Quantum Chem. 2013, 113, 2110.

(19) Lingard, H.; Han, J. T.; Thompson, A. L.; Leung, I. K. H.; Scott, R. T. W.; Thompson, S.; Hamilton, A. D. Angew. Chem. Int. Ed. 2014, 53, 3650 .

(20) Zhang, J.; Moore, J. S.; Xu, Z.; Aguirre, R. A.J. Am. Chem. Soc. 1992, 114, 2273.

(21) Kim, M.; Boissonnault, J. A.; Dau, P. V.; Cohen, S. M. Angew. Chem. Int. Ed. 2011, 50, 12193.

(22) General synthetic procedure for IEG growth deprotection: For TIPS deprotection, $4 \mathrm{M}$ solutions of the TIPS-protected derivatives 3-6 ( 1.0 equiv) in anhydrous $\mathrm{CH}_{2} \mathrm{Cl}_{2}$ were prepared under an inert-gas atmosphere. Next, a $1 \mathrm{M}$ solution of TBAF (1.5 equiv) in THF was added at room temperature and the reaction mixtures were stirred at room temperature for 1-2 h. Upon completion (monitored by TLC), the reaction mixtures were diluted with $\mathrm{CH}_{2} \mathrm{Cl}_{2}(25 \mathrm{~mL})$ and then washed with water $(3 \times 20 \mathrm{~mL})$ and brine $(20 \mathrm{~mL})$. Next, the organic layers were dried over anhydrous sodium sulfate, filtered, and the solvent was evaporated under reduced pressure. Any remaining catalyst was removed via a short flash column over silica gel (eluents: ethyl acetate/hexane mixtures). The TIPS-deprotected derivatives of the tetramer $\mathbf{5}$ and the octamer $\mathbf{6}$ were further purified with size-exclusion chromatography (stationary phase: BioBeads ${ }^{\mathrm{TM}} \mathrm{SX}-1$ Resin, eluent: $\mathrm{CH}_{2} \mathrm{Cl}_{2}$ ) before being carried forward to the Sonogashira coupling steps. Activation (via diazotization-iodination): Following a procedure adopted from Ref. 23 , the aniline derivatives 3-6 (1.0 equiv) were dissolved in acetonitrile to form $0.1 \mathrm{M}$ solutions. For compounds with low solubility in acetonitrile, toluene (10 vol\%) was added as a cosolvent. Next, a $6 \mathrm{M}$ aqueous $\mathrm{HCl}$ solution (10 vol\% of the total reaction solvent) was added to the reaction mixtures and the reaction mixtures were cooled in an ice-bath. Diazotization was then initiated by adding an aqueous solution of $\mathrm{NaNO}_{2}(1.1$ equiv) dropwise to the reaction mixtures at a reaction temperature of $<5{ }^{\circ} \mathrm{C}$. The reaction mixtures were then stirred at $\sim 0{ }^{\circ} \mathrm{C}$ for 15 minutes and subsequently added to ice-cold solutions of $\mathrm{KI}$ ( 3 equiv) in water. The resulting mixtures were again stirred at $0^{\circ} \mathrm{C}$ for $1 \mathrm{~h}$ and then extracted with ethyl acetate. The combined organic layers were washed with water and with brine, dried over anhydrous sodium sulfate, filtered, and the solvent was evaporated under reduced pressure. Finally, the crude activated (iodinated) derivatives of 3-6 obtained in this manner were run through short silica gel columns (eluent: ethyl acetate/hexane solvent mixtures) and then directly carried forward to the Sonogashira coupling reactions. Sonogashira couplings: To oven-dried reaction flasks were added (i) the iodo-derivative (1.0 equiv), (ii) $\mathrm{Pd}\left(\mathrm{PPh}_{34}\right.$ (3 $\mathrm{mol} \%$ ), and (iii) $\mathrm{CuI}$ (6 mol\%). The reaction flasks were then evacuated and backfilled with argon three times with standard Schlenk techniques. Next, the reaction flasks were charged with anhydrous DMF $(12 \mathrm{~mL})$ and triethylamine (2.0 equiv) followed by the TIPS-deprotected acetylene compounds (1.3 equiv). Finally, the reaction mixtures were stirred overnight at $70^{\circ} \mathrm{C}$. The progress of the reactions was monitored by TLC. Upon completion, the reaction mixtures were cooled to room temperature, filtered through Celite ${ }^{\circledR} 545$, and washed with ethyl acetate. The filtrates were diluted with water and the products were extracted with ethyl acetate. The combined organic layers were washed with water and brine, dried over anhydrous magnesium sulfate, filtered, and the 
solvent was evaporated under reduced pressure. The crude Sonogashira-coupled materials 4-7 were purified by flash column chromatography (eluents: ethyl acetate in hexane mixtures) and, for the longer derivatives 5-7, subsequent size-exclusion chromatography (stationary phase: Bio-Beads ${ }^{\mathrm{TM}}$ SX-1 Resin, eluent: $\mathrm{CH}_{2} \mathrm{Cl}_{2}$ ).

(23) Droz, A. S.; Neidlein, U.; Anderson, S.; Seiler, P.; Diederich, F. Helv. Chim. Acta 2001, 84, 2243.

(24) (a) Schumm, J. S.; Pearson, D. L.; Tour, J. M. Angew. Chem. Int. Ed. Engl. 1994, 33, 1360. (b) Arias-Marin, E.; Arnault, J. C.; Guillon, D.; Maillou, T.; Le Moigne, J.; Geffroy, B.; Nunzi, J. M. Langmuir 2000, 16, 4309. (c) Arias-Marin, E.; Le Moigne, J.; Maillou, T.; Guillon, D.; Moggio, I.; Geffroy, B. Macromolecules 2003, 36, 3570.

(25) Synthesis and characterization data of the dimer 4: Following the general reaction procedure for IEG growth (see: Ref. 22), the monomer 3 (2.0 mmol in $5 \mathrm{~mL} \mathrm{CH} \mathrm{Cl}_{2}$ ) was deprotected with TBAF to afford $1.11 \mathrm{~g}$ (95\% yield) of the TIPS-deprotected derivative of 3. At the same time, $\mathbf{3}(2.0 \mathrm{mmol})$ was activated following the general diazotization/iodination procedure to afford $1.06 \mathrm{~g}$ (57\% yield) of the iodinated derivative of 3 . The TIPS-deprotected $(2.6 \mathrm{mmol})$ and iodinated $(2.0 \mathrm{mmol})$ derivatives of 3 were then coupled together under Sonogashira coupling conditions to complete the IEG cycle, as detailed in the general IEG procedure. The crude product was purified by flash column chromatography (eluent: $0-20 \mathrm{vol} \%$ ethyl acetate in hexanes) to afford $1.72 \mathrm{~g}$ (88\% yield) of the dimer $4 .{ }^{1} \mathrm{H}$ NMR $\left(500 \mathrm{MHz}, \mathrm{CDCl}_{3}\right) \delta 8.19(\mathrm{~s}, 1 \mathrm{H}), 8.11(\mathrm{~s}, 1 \mathrm{H}), 8.04(\mathrm{~s}, 1 \mathrm{H}), 7.22$ $(\mathrm{s}, 1 \mathrm{H}), 6.06(\mathrm{~s}, 2 \mathrm{H}), 4.29-4.20(\mathrm{~m}, 8 \mathrm{H}), 1.74(\mathrm{dt}, J=12.0,5.8 \mathrm{~Hz}$, $2 \mathrm{H}), 1.67(\mathrm{td}, J=12.6,6.3 \mathrm{~Hz}, 2 \mathrm{H}), 1.55-1.28(\mathrm{~m}, 28 \mathrm{H})$, $1.27-1.20(\mathrm{~m}, 4 \mathrm{H}), 1.16-1.14(\mathrm{~m}, 21 \mathrm{H}), 0.98-0.82(\mathrm{~m}, 24 \mathrm{H}) .{ }^{13} \mathrm{C}$ $\left({ }^{1} \mathrm{H}\right)$ NMR $\left(125 \mathrm{MHz}, \mathrm{CDCl}_{3}\right) \delta 167.23,165.90,165.32,165.22$, 149.93, 137.99, 136.99, 136.85, 135.58, 135.15, 134.02, 123.84, 122.29, 118.67, 104.26, 99.30, 96.10, 89.23, 68.28, 68.19, 68.15, $67.49,60.52,38.95,38.92,38.87,30.60,30.48,30.44,29.12$, $29.06,29.05,29.03,24.06,23.94,23.90,23.82,23.08,23.04$, $18.79,17.83,14.18,14.14,12.42,11.49,11.14,11.03$. HRMS characterization for $\mathbf{4}$ was obtained after TIPS deprotection: HRMS (neg. ESI) calcd. for $\mathrm{C}_{52} \mathrm{H}_{74} \mathrm{NO}_{8}{ }^{-}: \mathrm{m} / z=840.5420$ [M $\mathrm{H}]^{-}$; found: 840.5421 .

(26) Synthesis and characterization data of the tetramer 5: Following the general reaction procedure for IEG growth (see: Ref. 22), the dimer 4 ( $1.0 \mathrm{mmol}$ in $\left.8 \mathrm{~mL} \mathrm{CH}_{2} \mathrm{Cl}_{2}\right)$ was deprotected with TBAF to afford $0.828 \mathrm{~g}$ (75\% yield) of the TIPS-deprotected derivative of $\mathbf{4}$. At the same time, $4(1.1 \mathrm{mmol})$ was activated following the general diazotization/iodination procedure to afford $1.038 \mathrm{~g}$ (62\% yield) of the iodinated derivative of 4 . The TIPS-deprotected $(1.3 \mathrm{mmol})$ and iodinated $(1.0 \mathrm{mmol})$ derivatives of $\mathbf{4}$ were then coupled together under Sonogashira coupling conditions to complete the IEG cycle, as detailed in the general IEG procedure. The crude product was purified by flash column chromatography (eluent: $0-20 \mathrm{vol} \%$ ethyl acetate in hexanes) to afford $0.910 \mathrm{~g}$ ( $82 \%$ yield) of the tetramer $5 .{ }^{1} \mathrm{H}$ NMR $\left(500 \mathrm{MHz}, \mathrm{CDCl}_{3}\right) \delta 8.28(\mathrm{~s}, 1 \mathrm{H}), 8.27(\mathrm{~s}, 1 \mathrm{H}), 8.24(\mathrm{~s}, 1 \mathrm{H}), 8.23$ $(\mathrm{s}, 1 \mathrm{H}), 8.21(\mathrm{~s}, 1 \mathrm{H}), 8.16(\mathrm{~s}, 1 \mathrm{H}), 8.12(\mathrm{~s}, 1 \mathrm{H}), 7.23(\mathrm{~s}, 1 \mathrm{H}), 6.07$ $(\mathrm{s}, 2 \mathrm{H}), 4.34-4.23(\mathrm{~m}, 16 \mathrm{H}), 1.79-1.67(\mathrm{~m}, 8 \mathrm{H}), 1.52-1.23(\mathrm{~m}, 64$ $\mathrm{H}), 1.16(\mathrm{~s}, 21 \mathrm{H}), 0.98-0.93(\mathrm{~m}, 6 \mathrm{H}), 0.91-0.84(\mathrm{~m}, 42 \mathrm{H}) .{ }^{13} \mathrm{C}$ $\left({ }^{1} \mathrm{H}\right)$ NMR $\left(125 \mathrm{MHz}, \mathrm{CDCl}_{3}\right) \delta 167.09,165.67,165.01,164.95$, 164.91, 164.76, 149.82, 137.88, 136.87, 136.14, 136.01, 135.86, $135.61,135.34,134.54,134.38,134.07,124.32,123.24,123.02$, 122.57, 121.95, 118.55, 113.21, 109.86, 103.93, 100.16, 96.47, 95.07, 94.72, 94.47, 94.15, 89.19, 68.27, 68.25, 68.18, 68.06,
$67.38,38.82,38.80,38.78,38.74,30.47,30.44,30.32,29.00$, 28.95, 28.92, 23.94, 23.84, 23.78, 23.73, 22.95, 22.92, 18.66, $14.06,14.03,11.35,11.00,10.91 . \sim 46{ }^{13} \mathrm{C}\left({ }^{1} \mathrm{H}\right)$ NMR resonances coincide with other signals. HRMS (pos. ESI) calcd. for $\mathrm{C}_{113} \mathrm{H}_{168} \mathrm{NO}_{16} \mathrm{Si}^{+}: \quad m / z=1823.2127 \quad[\mathrm{M}+\mathrm{H}]^{+} ; \quad$ found: 1823.2124.

(27) Synthesis and characterization data of the octamer 6: Following the general reaction procedure for IEG growth (see: Ref. 22), the tetramer $5\left(0.50 \mathrm{mmol}\right.$ in $\left.10 \mathrm{~mL} \mathrm{CH}_{2} \mathrm{Cl}_{2}\right)$ was deprotected with TBAF and the product was purified further via size exclusion chromatography (stationary phase: Bio-Beads ${ }^{\mathrm{TM}}$ SX-1 Resin, eluent: $\mathrm{CH}_{2} \mathrm{Cl}_{2}$ ) to afford $0.900 \mathrm{~g}$ (93\% yield) of the TIPS-deprotected derivative of $\mathbf{5}$. At the same time, $\mathbf{5}$ $(0.32 \mathrm{mmol})$ was activated following the general diazotization/iodination procedure to afford $0.413 \mathrm{~g}$ (67\% yield) of the iodinated derivative of $\mathbf{5}$. The TIPS-deprotected $(0.27 \mathrm{mmol})$ and iodinated $(0.21 \mathrm{mmol})$ derivatives of 5 were then coupled together under Sonogashira coupling conditions to complete the IEG cycle, as detailed in the general IEG procedure. The crude product was purified by flash column chromatography (eluent: $0-20$ vol\% ethyl acetate in hexanes) to afford $0.200 \mathrm{~g}$ (27\% yield) of the octamer 6. ${ }^{1} \mathrm{H} \mathrm{NMR}\left(500 \mathrm{MHz}, \mathrm{CDCl}_{3}\right) \delta$ 8.29 (dd, $J=5.0,2.8 \mathrm{~Hz}, 10 \mathrm{H}), 8.25(\mathrm{~s}, 1 \mathrm{H}), 8.23(\mathrm{~s}, 1 \mathrm{H}), 8.21$ (s, $1 \mathrm{H}), 8.16(\mathrm{~s}, 1 \mathrm{H}), 8.12(\mathrm{~s}, 1 \mathrm{H}), 7.24(\mathrm{~s}, 1 \mathrm{H}), 6.06(\mathrm{~s}, 2 \mathrm{H})$, 4.34-4.22 (m, $32 \mathrm{H}), 1.78-1.68(\mathrm{~m}, 16 \mathrm{H}), 1.52-1.22(\mathrm{~m}, 128 \mathrm{H})$, $1.16(\mathrm{~s}, 21 \mathrm{H}), 0.98-0.93(\mathrm{~m}, 9 \mathrm{H}), 0.92-0.84(\mathrm{~m}, 87 \mathrm{H})$. MS (MALDI, DCTB matrix) calcd. for $\mathrm{C}_{217} \mathrm{H}_{311} \mathrm{NNaO}_{32} \mathrm{Si}^{+}: \mathrm{m} / \mathrm{z}=$ $3494.2401[\mathrm{M}+\mathrm{Na}]^{+}$; found: 3494.3000 .

(28) Synthesis and characterization data of the hexadecamer 7 : Following the general reaction procedure for IEG growth (see: Ref. 22), the tetramer $6\left(0.017 \mathrm{mmol}\right.$ in $\left.5 \mathrm{~mL} \mathrm{CH}_{2} \mathrm{Cl}_{2}\right)$ was deprotected with TBAF and the product was purified further via size exclusion chromatography (stationary phase: Bio-Beads ${ }^{\mathrm{TM}}$ SX-1 Resin, eluent: $\mathrm{CH}_{2} \mathrm{Cl}_{2}$ ) to afford $0.056 \mathrm{~g}$ (95\% yield) of the TIPS-deprotected derivative of $\mathbf{6}$. At the same time, 6 $(0.029 \mathrm{mmol})$ was activated following the general diazotization/iodination procedure to afford $0.073 \mathrm{~g}$ (53\% yield) of the iodinated derivative of 6 . The TIPS-deprotected $(0.017 \mathrm{mmol})$ and iodinated $(0.015 \mathrm{mmol})$ derivatives of 6 were then coupled together under Sonogashira coupling conditions to complete the IEG cycle, as detailed in the general IEG procedure. The crude product was purified by flash column chromatography (eluent: $0-20 \mathrm{vol} \%$ ethyl acetate in hexanes) and further via size exclusion chromatography (stationary phase: Bio-Beads ${ }^{\mathrm{TM}} \mathrm{SX}-1$ Resin, eluent: $\mathrm{CH}_{2} \mathrm{Cl}_{2}$ ) to afford $0.020 \mathrm{~g}(19 \%$ yield $)$ of the hexadecamer $7 .{ }^{1} \mathrm{H}$ DOSY NMR ( $500 \mathrm{MHz}, \mathrm{CDCl}_{3}$, polystyrene standard, see Figure $\mathrm{S} 1$ for the calibration curve): $M_{\mathrm{w}}=6.9 \mathrm{kDa}$ (expected: $6.8 \mathrm{kDa}$ ).

(29) See Supplementary Figures $\mathrm{S} 12$ and $\mathrm{S} 13$ for the ${ }^{13} \mathrm{C}\left({ }^{1} \mathrm{H}\right)$ NMR spectra $\left(125 \mathrm{MHz}, \mathrm{CDCl}_{3}, 298 \mathrm{~K}\right)$ as well as for the ${ }^{1} \mathrm{H}_{-}{ }^{13} \mathrm{C} \mathrm{HMBC}$ NMR spectra ( $500 \mathrm{MHz}, \mathrm{CDCl}_{3}, 298 \mathrm{~K}$ ) of 6 and 7. With over 200 carbon atoms in $\mathbf{6}$ and over 400 carbon atoms in 7, a large percentage of carbon signals is coinciding and/or is showing relatively weak signal-to-noise ratios. Yet, there are no carbon signals observed in the 80-85 ppm regions, where one would expect to find ${ }^{13} \mathrm{C}$ resonances for potential homocoupled diacetylene byproducts (see, e.g., Ref. 33 for the ${ }^{13} \mathrm{C}\left({ }^{1} \mathrm{H}\right)$ NMR spectra of ester-containing diacetylene derivatives with similar structures). Taken together with the observed (see: Refs. 27 and 28) molecular weights - and the fact that the ${ }^{1} \mathrm{H}$ NMR resonances corresponding to the TIPS protecting groups are clearly observed at $\sim 1.16 \mathrm{ppm}$ with the proper integrations - 
Organic Materials

this finding excludes the formation of homocoupled diacetylene derivatives as potential side-products.

(30) Xue, C.; Luo, F.-T. Tetrahedron 2004, 60, 6285.

(31) Sharafi, M.; Campbell, J. P.; Rajappan, S. C.; Dudkina, N.; Gray, D. L.; Woods, T. J.; Li, J.; Schneebeli, S. T. Angew. Chem. Int. Ed. 2017, 56, 7097.
(32) Since a racemic mixture of 2-ethylhexyl bromide was used for the synthesis, the OPEs are present as a mixture of diastereoisomers, which could further contribute to the observed linebroadening of the UV/Vis spectra.

(33) Vestergaard, M.; Jennum, K.; Sørensen, J. K.; Kilså, K.; Nielsen, M. B. J. Org. Chem. 2008, 73, 3175. 